\title{
Protective effects of dexmedetomidine on hypoxia/reoxygenation injury in cardiomyocytes by regulating the CHOP signaling pathway
}

\author{
XIAOQIAO SHI ${ }^{1}$, ZHIWEN LIU $^{1}$ and JUNWEI $\mathrm{LI}^{2}$ \\ ${ }^{1}$ Department of Anesthesiology, The Second Affiliated Hospital of University of South China, Hengyang, \\ Hunan 421001; ${ }^{2}$ Department of Anesthesiology, The Second Affiliated Hospital of Hunan University \\ of Traditional Chinese Medicine, Changsha, Hunan 410005, P.R. China
}

Received September 10, 2019; Accepted March 2, 2020

DOI: $10.3892 / \mathrm{mmr} .2020 .11442$

\begin{abstract}
Hypoxia/reoxygenation (H/R) injury in myocardial cells occurs frequently during cardiac surgery and affects the prognosis of patients. The present study aimed to investigate the protective effects of dexmedetomidine (Dex) on H/R injury and its association with the C/EBP-homologous protein (CHOP) signaling pathway. An H/R model was constructed in $\mathrm{H} 9 \mathrm{C} 2$ cells to investigate the effects of Dex on H/R injury. Cell viability, apoptosis and lactate dehydrogenase (LDH) levels were determined by MTT, flow cytometry and 2,4-dinitrophenylhydrazine colorimetric assays, respectively. The expression levels of inflammatory factors were measured by reverse transcription-quantitative PCR (RT-qPCR), and CHOP and glucose-regulated protein-78 (Grp78) expression levels were detected by RT-qPCR and western blotting. CHOP was overexpressed or knocked down to detect the cell viability, apoptosis, LDH level and the expression levels of inflammatory factors and Grp78. The results demonstrated that in the $\mathrm{H} / \mathrm{R}$ group, cell viability was lower and apoptosis was higher, and that higher levels of LDH and inflammatory factors were present compared with those in the Dex $+\mathrm{H} / \mathrm{R}$ group. Silencing of CHOP significantly reversed the H/R-reduced cell viability, high apoptotic rate and LDH levels, as well as the elevated expression levels of inflammatory factors and Grp78 caused by H/R injury, whereas the overexpression of CHOP inhibited cell viability and promoted apoptosis, elevated LDH level and expression of inflammatory factors and Grp78 compared with the negative control. Additionally, pretreatment with Dex significantly alleviated the H/R injury; thus, Dex may
\end{abstract}

Correspondence to: Dr Junwei Li, Department of Anesthesiology, The Second Affiliated Hospital of Hunan University of Traditional Chinese Medicine, 233 North Cai'e Road, Changsha, Hunan 410005, P.R. China

E-mail: junweil_lijw@163.com

Key words: dexmedetomidine, hypoxia/reoxygenation injury, cardiomyocytes, C/EBP-homologous protein, cell proliferation protect $\mathrm{H} 9 \mathrm{C} 2$ cells against H/R induced cell injury, possibly by suppressing the CHOP signaling pathway.

\section{Introduction}

Ischemic reperfusion (I/R) commonly occurs after shock therapy, artery bypass and cardiopulmonary cerebral resuscitation (1-3). The functions of tissues and organs normally recover after I/R; however, I/R injury may aggravate and cause severe complications, including stroke (4). The outcome of myocardial surgery I/R is closely associated with the occurrence of myocardial ischemic reperfusion injury (MIRI). Previous studies have reported that oxygen free radical injury (5), energy metabolism disorder in cardiomyocytes (6), calcium overload (7), apoptosis of cardiomyocytes and other inflammatory diseases (8-10) serve important roles in MIRI. During reperfusion, a large amount of inflammatory factors is produced to promote tissue infiltration of inflammatory cells, thus affecting cell structures and functions (11). Hypoxia/reoxygenation $(H / R)$ in cells is a major characteristic of $I / R$, and is frequently used to simulate the activity of $\mathrm{I} / \mathrm{R}(12,13)$. Low cell viability, high apoptosis and inflammatory responses occur after cell injury induced by H/R (14).

Dexmedetomidine (Dex) is a new $\alpha 2$-adrenergic receptor agonist with high selectivity that and exerts analgesic (15), anti-stress (16) and anti-inflammatory (17) effects. Chen et al (18) have demonstrated that Dex exerts protective effects on postoperative cognitive dysfunction by downregulating the expression levels of inflammatory factors interleukin (IL)-1 $\beta$, tumor necrosis factor (TNF)- $\alpha$ and $N F-\kappa B$ in rats. Wang et al (19) have investigated the mechanism of lidocaine-induced cytotoxicity and reported that the anti-inflammatory effect of Dex may be achieved by suppressing the mitogen-activated protein kinase (MAPK) signaling pathway to affect the expression of caspase- 3 and Bcl-2 and reduce apoptosis. Additionally, Dex has been reported to reduce the expression of macrophage inflammatory protein- 2 and other cytokines (TNF- $\alpha$, IL- 6 and IL-1 $\beta$ ) in rat lung cells (20). Through regulating the peroxisome proliferator-activated receptor- $\gamma$ coactivator (PGC)- $1 \alpha$ signaling pathway, Dex alleviates encephala edema and apoptosis in the 
presence of PGC-1 $\alpha$ expression, thus protecting neurons from oxidative stress (21). In addition, Liu et al (22) explored the effects of Dex on injury caused by ischemia in neuronal cells, and the results demonstrated that Dex promoted neuronal cell viability and reduced apoptosis, as well as the ratio of $\mathrm{Bax} / \mathrm{Bcl}-2$ expression levels. In the present study, an $\mathrm{H} / \mathrm{R}$-induced H9C2 cell model was constructed and pretreated with Dex to investigate the protective effects of Dex on H/R injury in cardiomyocytes and its mechanism in the $\mathrm{C} / \mathrm{EBP}$-homologous protein $(\mathrm{CHOP})$ signaling pathway.

\section{Materials and methods}

Cell culture and grouping. The H9C2 (2-1) cell line was obtained from The Cell Bank of Type Culture Collection of the Chinese Academy of Sciences (cat. no. GNR 5). The cells were incubated in 90\% DMEM (GIBCO; Thermo Fisher Scientific, Inc.) containing 10\% FBS (Gibco; Thermo Fisher Scientific, Inc.) and $100 \mathrm{U} / \mathrm{ml}$ penicillin and $0.1 \mathrm{mg} / \mathrm{ml}$ streptomycin (Sigma-Aldrich; Merck KGaA) with $5 \% \mathrm{CO}_{2}$ at $37^{\circ} \mathrm{C}$. The cells were divided into control, Dex, H/R, and Dex+H/R groups. The control group was normally cultured; Dex group was pretreated with $1 \mu \mathrm{M}$ Dex (Beijing Huamaike Biotechnology Co., Ltd.) for $1 \mathrm{~h}$ and cultured normally; the $\mathrm{H} / \mathrm{R}$ group was deoxidized using $4 \mathrm{mM}$ sodium dithionite for $1 \mathrm{~h}$ and reoxidized for $12 \mathrm{~h}$; the Dex+H/R group was pretreated with $1 \mu \mathrm{M}$ Dex followed by $\mathrm{H} / \mathrm{R}$ treatment.

Cell transfection. Cell transfection was performed as previously described (23). Small interfering (si)RNA targeting CHOP (siCHOP; cat. no. siB078266608-1-5; Guangzhou RiboBio Co.), si-negative control (NC; siNC; cat. no. siN0000002-1-5), pCMV6-XL5-CHOP (cat. no. SC117581; Origene Technologies, Inc.) and its $\mathrm{NC}$ overexpression vector (pCMV6-XL5; cat. no. PCMV6XL5; Origene Technologies, Inc.) were dissolved in $50 \mu \mathrm{l}$ DMEM (HyClone; GE Healthcare Life Sciences) and used to overexpress or knock down the expression of CHOP. Prior to cell transfection, the cells were digested, thoroughly mixed, seeded into a 6-well plate $\left(1 \times 10^{6}\right.$ cells $\left./ \mathrm{ml}\right)$ and evenly distributed in an orifice plate. After culturing overnight until the cells reached 60-70\% confluency, the cells were transfected with 20 pmol siCHOP, CHOP siNC and NC in DMEM using Lipofectamine ${ }^{\circledR} 2000$ transfection reagent (Thermo Fisher Scientific, Inc.) for $48 \mathrm{~h}$ at $37^{\circ} \mathrm{C}$. At $24 \mathrm{~h}$ post-transfection, reverse transcription-quantitative $\mathrm{PCR}$ (RT-qPCR) and western blotting were used to detect the transfection efficiency. After the transfection, the H9C2 cells were divided into control, H/R, Dex $+\mathrm{H} / \mathrm{R}$, siNC+Dex $+\mathrm{H} / \mathrm{R}$ and siCHOP + Dex $+H / R$ groups to detect the effects of silencing CHOP on $H / R$ injury to the cells, whereas those in the $H / R$, $\mathrm{Dex}+\mathrm{H} / \mathrm{R}, \mathrm{NC}+\mathrm{Dex}+\mathrm{H} / \mathrm{R}, \mathrm{CHOP}+\mathrm{Dex}+\mathrm{H} / \mathrm{R}$ groups were used to explore the effects of CHOP overexpression in $\mathrm{H} 9 \mathrm{C} 2$ cells.

MTT assay. H9C2 cells were seeded $\left(2 \times 10^{4}\right.$ cells/well) into 96-well plates. MTT (10 $\mu \mathrm{l}$; Amresco) was added to each well and cultured for $4 \mathrm{~h}$ at room temperature. Subsequently, $100 \mu \mathrm{l}$ DMSO (Sigma-Aldrich; Merck KGaA) was added into each well and gently agitated for $10 \mathrm{~min}$ at room temperature. The optical density (OD) was detected using a microplate reader at $490 \mathrm{~nm}$.
Table I. Primer sequences used for RT-qPCR.

\begin{tabular}{|c|c|}
\hline Primer & Sequences $\left(5^{\prime} \rightarrow 3^{\prime}\right)$ \\
\hline \multirow[t]{2}{*}{ TNF- $\alpha$} & Forward: ATGGGCTCCCTCTCATCAGT \\
\hline & Reverse: GCTTGGTGGTTTGCTACGAC \\
\hline \multirow[t]{2}{*}{ IL-1 $\beta$} & Forward: TCCTCGTGACTCGTGGGAT \\
\hline & Reverse: GGTGTGCAGATGCCGGTTCAG \\
\hline \multirow[t]{2}{*}{ IL-6 } & Forward: CCAGTTGCCTTCTTGGGACT \\
\hline & Reverse: GGTCTGTTGTGGGTGGTATCC \\
\hline \multirow[t]{2}{*}{ Grp78 } & Forward: GGTGCAGCAGGACATCAAGTT \\
\hline & Reverse: CCCACCTCCAATATCAACTTGA \\
\hline \multirow[t]{2}{*}{$\mathrm{CHOP}$} & Forward: CTGGAAGCCTGGTATGAGGAT \\
\hline & Reverse: CAGGGTCAAGAGTAGTGAAGGT \\
\hline \multirow[t]{2}{*}{ GAPDH } & Forward: AGAAGGCTGG GGCTCATTTG \\
\hline & Reverse: AGGGGCCATC CACAGTCTTC \\
\hline
\end{tabular}

TNF, tumor necrosis factor; IL, interleukin; Grp78, glucose-regulated protein-78; CHOP, C/EBP-homologous protein; GAPDH, glyceraldehyde-3-phosphate dehydrogenase.

2,4-dinitrophenylhydrazine colorimetric assay. The cells were collected and centrifuged at $255 \mathrm{x}$ g for $2 \mathrm{~min}$ at room temperature to obtain the supernatant. The lactate dehydrogenase (LDH) levels were determined by 2,4-dinitrophenylhydrazine colorimetric assay (cat. no. A020-1-2; Nanjing Jiancheng Bioengineering Institute) according to the manufacturer's instructions. The OD value was determined using a microplate reader at $440 \mathrm{~nm}$.

Flow cytometry. Early and late apoptosis were detected by flow cytometry to explore the effects of Dex, overexpression or knockdown of CHOP on $\mathrm{H} 9 \mathrm{C} 2$ cells using the FITC/propidium iodide (PI) Apoptosis Detection Kit [cat. no. 70-AP101-100; Multisciences (Lianke) Biotech Co., Ltd.]. The cells were centrifuged at $1,000 \mathrm{x} \mathrm{g}$ at $4^{\circ} \mathrm{C}$ for $5 \mathrm{~min}$ to collect the sediments, blocked with $70 \%$ ethanol for $2 \mathrm{~h}$ at $4^{\circ} \mathrm{C}$ and dyed with Annexin V-fluorescein isothiocyanate and PI. Finally, the cells were analyzed by flow cytometry (BD FACScanto II; BD Biosciences) and FlowJo software (version 7.6.1; FlowJo LLC).

$R T-q P C R$. The relative mRNA expression levels of TNF- $\alpha$, IL-1 $\beta$, IL-6, CHOP and $78 \mathrm{kDa}$ glucose-regulated protein (Grp78) in H9C2 cells were determined by RT-qPCR. Total RNAs were extracted from H9C2 cells using QIAshredder and an RNeasy Kit (Qiagen $\mathrm{GmbH}$ ), and the RNA concentration was detected. A total of $1.0 \mu \mathrm{g}$ RNA was reverse transcribed into cDNA using SuperScirpt ${ }^{\mathrm{TM}}$ II Reverse Transcriptase (Thermo Fisher Scientific, Inc.) with $5 \mu$ l First-Strand Buffer, $1 \mu \mathrm{dNTP}$ mix and $100 \mathrm{ng}$ primers at $37^{\circ} \mathrm{C}$ for $60 \mathrm{~min}$ and $4^{\circ} \mathrm{C}$ for $5 \mathrm{~min}$. Subsequently, qPCR was performed using SYBR Fast qPCR Mix (Invitrogen; Thermo Fisher Scientific, Inc.). The following thermocycling conditions were used for qPCR: Initial denaturation at $95^{\circ} \mathrm{C}$ for $15 \mathrm{~min}$; denaturation $95^{\circ} \mathrm{C}$ for $10 \mathrm{sec} ; 40$ cycles at $60^{\circ} \mathrm{C}$ for $30 \mathrm{sec}$ (annealing) and at $72^{\circ} \mathrm{C}$ for $30 \mathrm{sec}$ (extension); and final extension at $72^{\circ} \mathrm{C}$ for $7 \mathrm{~min}$. 

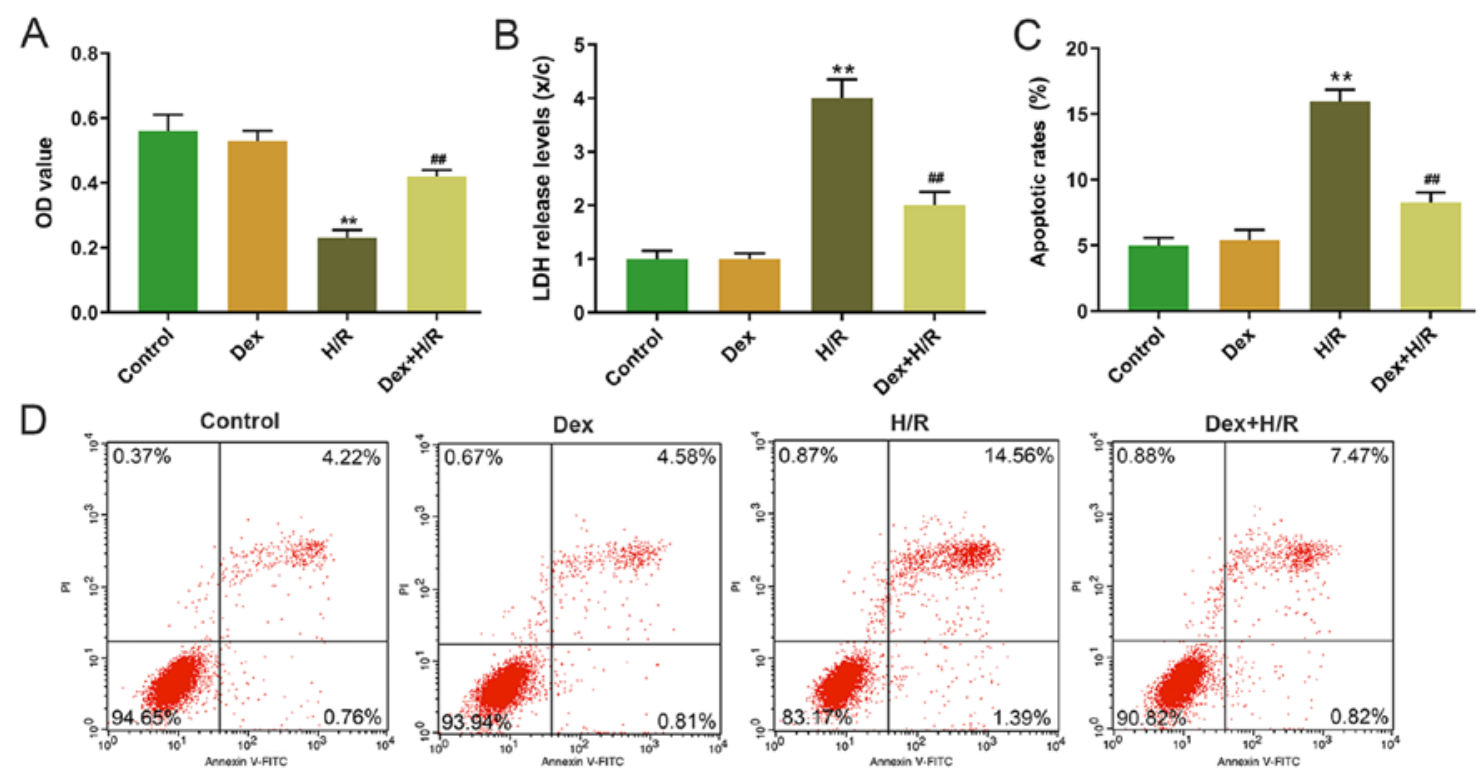

Figure 1. Effects of H/R and Dex on cell viability, LDH level and apoptosis in H9C2 cells. (A) Cell viability of H9C2 cells was determined by MTT assay at $24 \mathrm{~h}$. (B) LDH levels of $\mathrm{H} 9 \mathrm{C} 2$ cells were determined by 2,4-dinitrophenylhydrazine colorimetric assay. (C and D) Apoptotic rates of H9C2 cells were determined by flow cytometry. ${ }^{* *} \mathrm{P}<0.001$ vs. control; ${ }^{\# \#} \mathrm{P}<0.001$ vs. H/R. H/R, hypoxia/reoxygenation; Dex, dexmedetomidine; LDH, lactate dehydrogenase; OD, optical density; PI, propidium iodide.

The expression levels of RT-qPCR products were determined by the $2^{-\Delta \Delta C q}$ method (24). GADPH served as the internal reference, and the primer sequences are presented in Table I.

Western blotting. The protein expression levels of CHOP and Grp78 were measured by western blotting. The total proteins of H9C 2 cells were harvested by radioimmunoprecipitation assay buffer (Beyotime Institute of Biotechnology), and the protein concentration was measured by a bicinchoninic acid protein assay (Bio-Rad Laboratories, Inc.). The proteins (20 $\mu \mathrm{g} / \mathrm{lane})$ were separated by SDS-PAGE and electrotransferred to PVDF membranes, which were blocked with 5\% skimmed milk at room temperature for $1 \mathrm{~h}$. The membranes were then incubated with CHOP (1:200; cat. no. ab11419; Abcam), Grp78 (1:100; cat. no. ab21685; Abcam) and GAPDH (1:10,000; cat. no. ab181602; Abcam) primary antibodies at $4^{\circ} \mathrm{C}$ overnight. The membranes were rinsed with TBST $(0.05 \%$ Tween- 20$)$ and incubated with the specific horseradish peroxide-conjugated secondary antibodies for CHOP (goat anti-mouse; 1:2,000; cat. no. ab205719; Abcam), Grp78 (goat anti-rabbit; 1:5,000; cat. no. ab205718; Abcam) and GAPDH (goat anti-rabbit; 1:1,000; cat. no. ab6721; Abcam) for $2 \mathrm{~h}$ at room temperature. The protein bands were visualized by enhanced chemiluminescence reagent (Thermo Fisher Scientific, Inc.). Protein expression was quantified using Quantity One software (version 4.4; Bio-Rad Laboratories, Inc.).

ELISA. The cells were treated and suspended, the culture supernatants were collected into a 1-ml centrifuge tube and centrifuged at $3,000 \mathrm{x} \mathrm{g}$ for $10 \mathrm{~min}$ at room temperature, and the supernatant was collected. The levels of superoxide dismutase (SOD), nitric oxide (NO) and malondialdelyde (MDA) were measured using ELISA kits (SOD, cat. no. 19160; Sigma-Aldrich; Merck KGaA; NO, cat. no. S0021; Beyotime Institute of Biotechnology; MDA, cat. no. MAK085c;
Sigma-Aldrich; Merck KGaA) according to the manufacturers' instructions. The absorbance was measured at $450 \mathrm{~nm}$ using an Infinite M200 PRO microplate reader (Tecan Group, Ltd.).

Statistical analysis. SPSS 17.0 (SPSS, Inc.) software was used for data analysis. The data are presented as the mean \pm standard deviation from three independent experiments. One-way ANOVA with Tukey's post hoc test was used for multiple group analysis. $\mathrm{P}<0.05$ was considered to indicate a statistically significant difference.

\section{Results}

Effects of Dex on cell viability, LDH level, apoptosis and expression of inflammatory factors in $\mathrm{H} 9 \mathrm{C} 2$ cells. The $\mathrm{H} 9 \mathrm{C} 2$ cells were induced by $\mathrm{H} / \mathrm{R}$, and cell viability was detected by MTT assay. The results demonstrated that $\mathrm{H} 9 \mathrm{C} 2$ cell viability was significantly lower in the H/R group compared with that in the control group, and that the Dex $+\mathrm{H} / \mathrm{R}$ group exhibited significantly higher cell viability compared with that in the H/R group (Fig. 1A). Additionally, LDH levels were significantly higher in the H/R group compared with the control and Dex + H/R groups (Fig. 1B). The results also demonstrated a higher apoptotic rate in the H/R group compared with that in the control group, and the apoptotic rate was significantly lower in the Dex $+H / R$ group compared with the H/R group (Fig. 1C and D). In the H/R group, the expression levels of TNF- $\alpha$, IL-1 $\beta$ and IL- 6 were significantly higher compared with those in the control group, whereas the levels of TNF- $\alpha$, IL- $1 \beta$ and IL- 6 were significantly lower in the Dex $+H / R$ group compared with those in the H/R group (Fig. 2A).

Dex affects the CHOP signaling pathway. CHOP and Grp78 expression levels were determined by RT-qPCR and western blotting. Both mRNA and protein expression levels of CHOP 

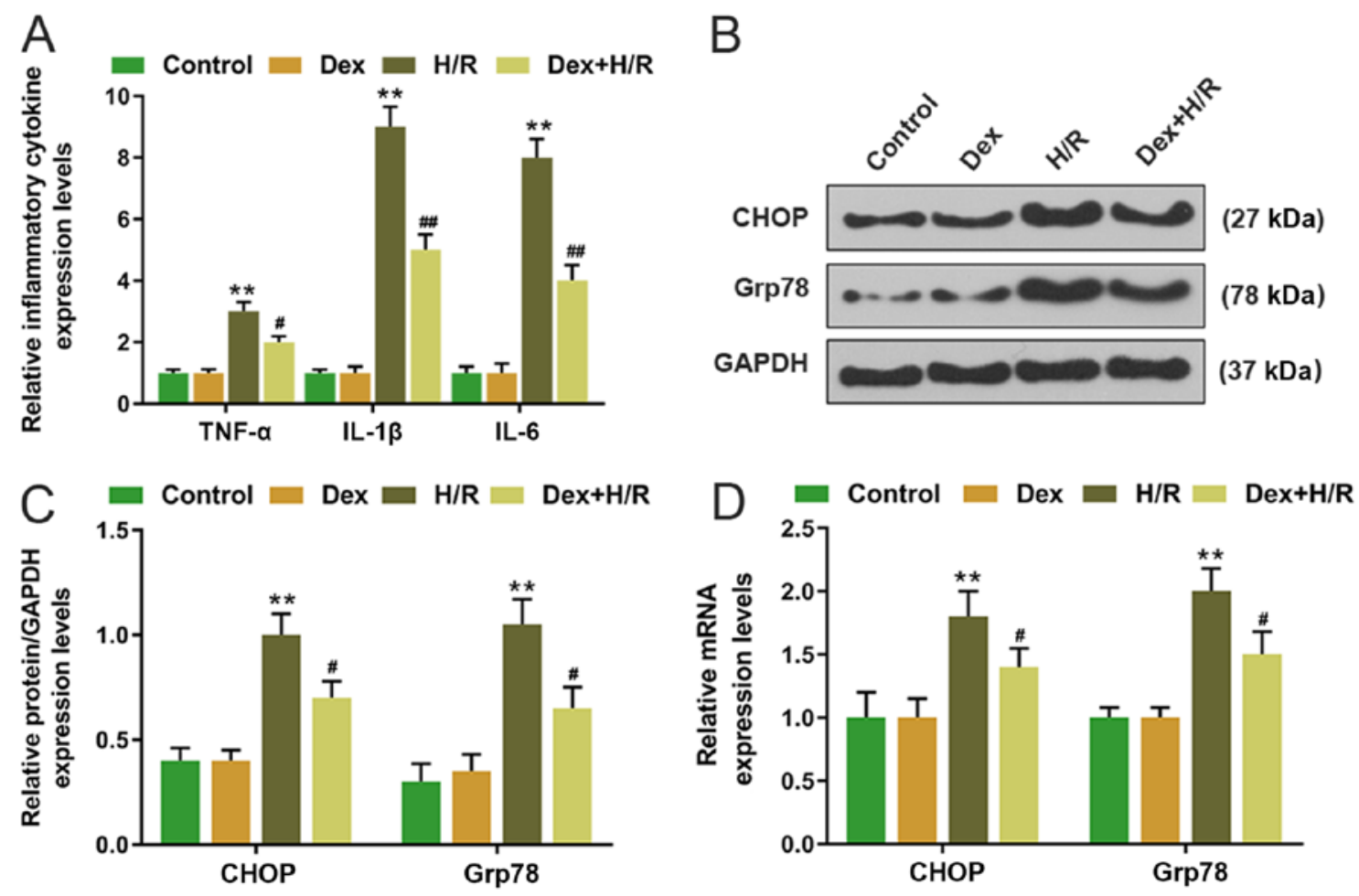

Figure 2. Expression levels of inflammatory factors and the CHOP signaling pathway in H9C2 cells. (A) Expression levels of TNF- $\alpha$, IL-1 $\beta$ and IL-6 in H9C2 cells determined by RT-qPCR. (B-D) Expression levels of CHOP and Grp78 in H9C2 cells were determined by (B and C) western blotting and (D) RT-qPCR. ${ }^{* *} \mathrm{P}<0.001$ vs. control; " $\mathrm{P}<0.05,{ }^{\# \#} \mathrm{P}<0.001$ vs. H/R. CHOP, C/EBP-homologous protein; TNF, tumor necrosis factor; IL, interleukin; RT-qPCR, reverse transcription-quantitative PCR; Dex, dexmedetomidine; H/R, hypoxia/reoxygenation.
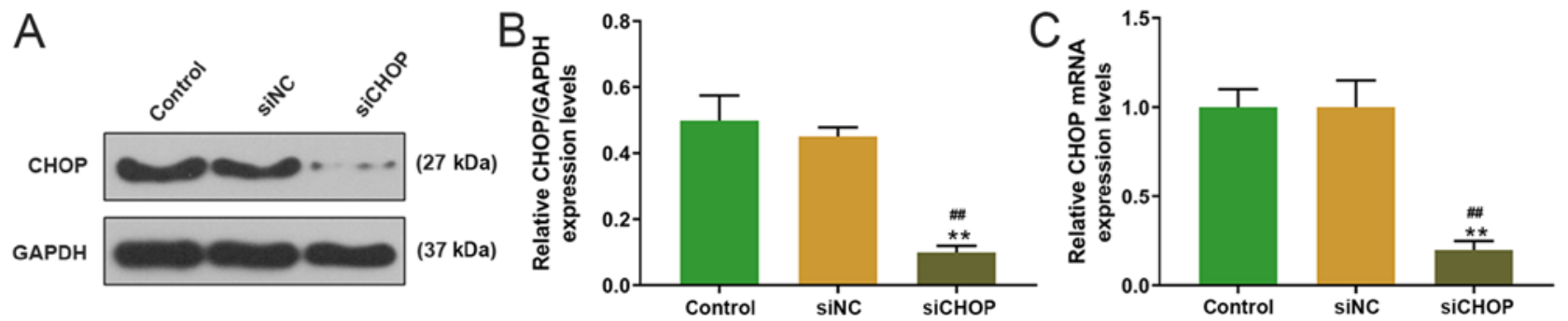

Figure 3. Transfection efficiency of siCHOP in H9C2 cells. (A and B) CHOP protein and (C) mRNA expression levels relative to GAPDH in control cells or cells transfected with siNC or siCHOP were determined by (A and B) western blotting and (C) RT-qPCR, respectively. ${ }^{* *} \mathrm{P}<0.001 \mathrm{vs}$. control; ${ }^{\# \#} \mathrm{P}<0.001 \mathrm{vs}$. siNC, CHOP, C/EBP-homologous protein; si, small interfering; NC, negative control; RT-qPCR, reverse transcription-quantitative PCR.

and Grp78 were significantly upregulated in the H/R group compared with the control group, whereas in the Dex-+H/R group, CHOP and Grp78 expression levels were significantly lower compared with those in the H/R group (Fig. 2B-D).

Effects of silencing CHOP on cell viability, LDH level, apoptosis and expression of inflammatory factors and Grp78 in H9C2 cells. siCHOP was transfected into H9C2 cells, and the transfection efficiency was measured by western blotting. The expression of $\mathrm{CHOP}$ in the siCHOP group was significantly lower compared with the control and siNC groups (Fig. 3). In addition, MTT assay revealed that the cell viability was significantly higher in the siCHOP+Dex $+\mathrm{H} / \mathrm{R}$ group compared with the siNC+Dex+H/R group (Fig. 4A). In addition, the $\mathrm{LDH}$ levels and apoptotic rates were significantly lower in the siCHOP+ Dex+H/R group compared with the H/R and siNC+ Dex $+H / R$ groups (Fig. 4B-D). In the H/R group, the expression levels of TNF- $\alpha$, IL-1 $\beta$ and IL- 6 were significantly higher compared with the control group; by contrast, the expression levels of TNF- $\alpha$, IL-1 $\beta$ and IL- 6 were significantly lower in the $\mathrm{Dex}+\mathrm{H} / \mathrm{R}$ and $\mathrm{siCHOP}+\mathrm{Dex}+\mathrm{H} / \mathrm{R}$ groups compared with the H/R and siNC+ Dex+H/R groups (Fig. 5A). Furthermore, the protein and mRNA expression levels of Grp78 were significantly elevated in the H/R group compared with the control, whereas the expression levels of Grp78 were lower in the Dex+H/R and siCHOP+ Dex+H/R groups compared with the $\mathrm{H} / \mathrm{R}$ and siNC+H/R groups (Fig. $5 \mathrm{~B}-\mathrm{D}$ ).

Effects of CHOP overexpression on cell viability, $\mathrm{LDH}$ level, apoptosis and expression of inflammatory factors and Grp78 in H9C2 cells. The CHOP overexpression plasmid was transfected into $\mathrm{H} 9 \mathrm{C} 2$ cells, and significantly higher levels of CHOP were observed in the CHOP group compared with the control and NC groups (Fig. 6A-C). The effect of $\mathrm{CHOP}$ 

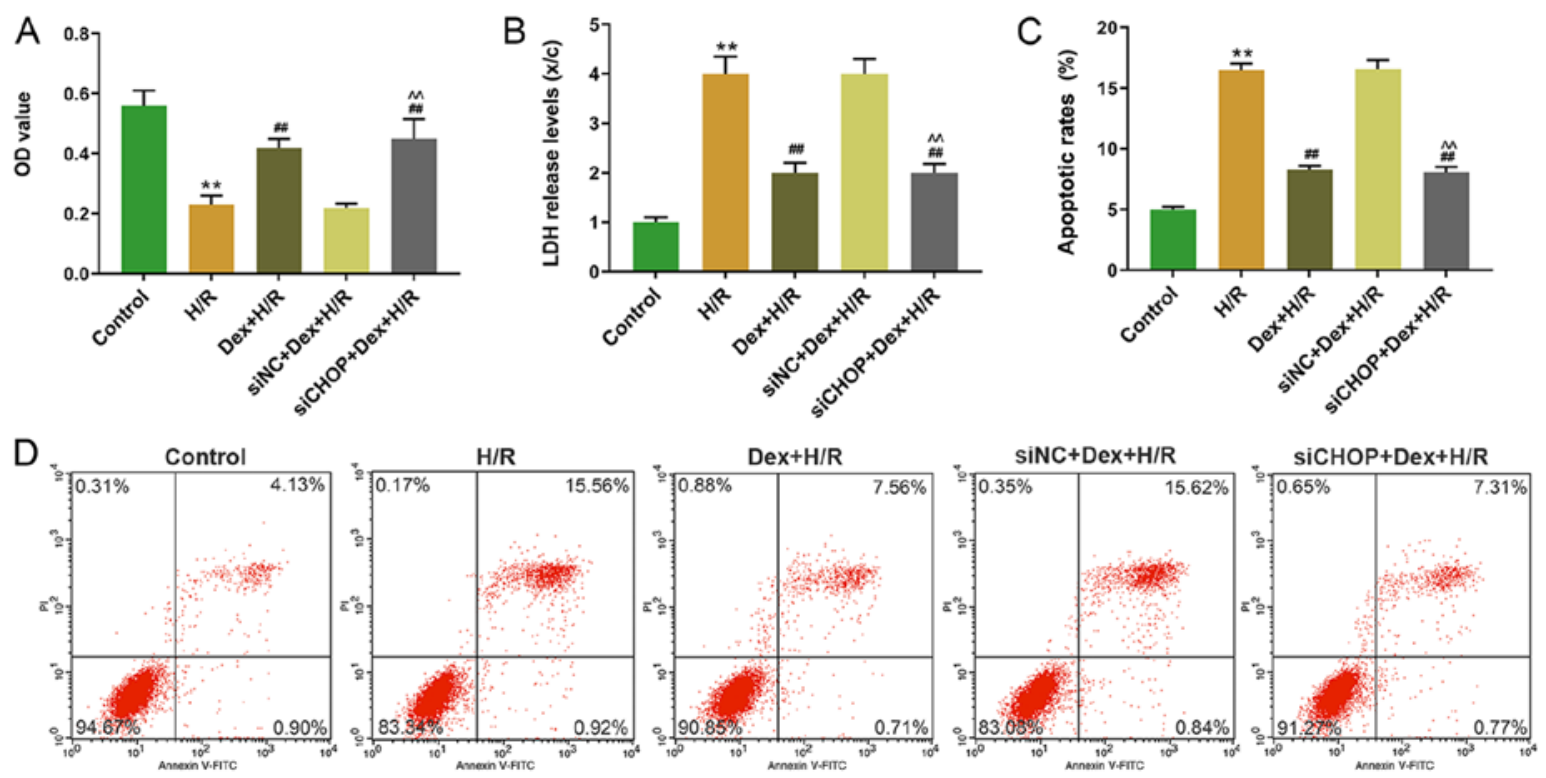

Figure 4. Effects of CHOP silencing on cell viability, LDH level and apoptosis in H9C2 cells. (A) Cell viability of H9C2 cells was determined by MTT assay at $24 \mathrm{~h}$. (B) LDH levels of $\mathrm{H} 9 \mathrm{C} 2$ cells were determined by 2,4-dinitrophenylhydrazine colorimetric assay. (C and D) Apoptotic rates of H9C2 cells were determined by flow cytometry. ${ }^{* *} \mathrm{P}<0.001$ vs. control; ${ }^{\# \#} \mathrm{P}<0.001$ vs. $\mathrm{H} / \mathrm{R} ;{ }^{\wedge} \mathrm{P}<0.001$ vs. siNC+Dex+HR. CHOP, C/EBP-homologous protein; LDH, lactate dehydrogenase, H/R, hypoxia/reoxygenation; Dex, dexmedetomidine; si, small interfering; NC, negative control; OD, optical density; PI, propidium iodide.

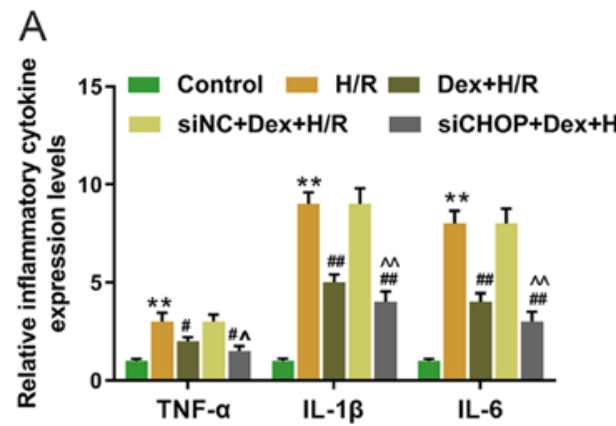

A

B
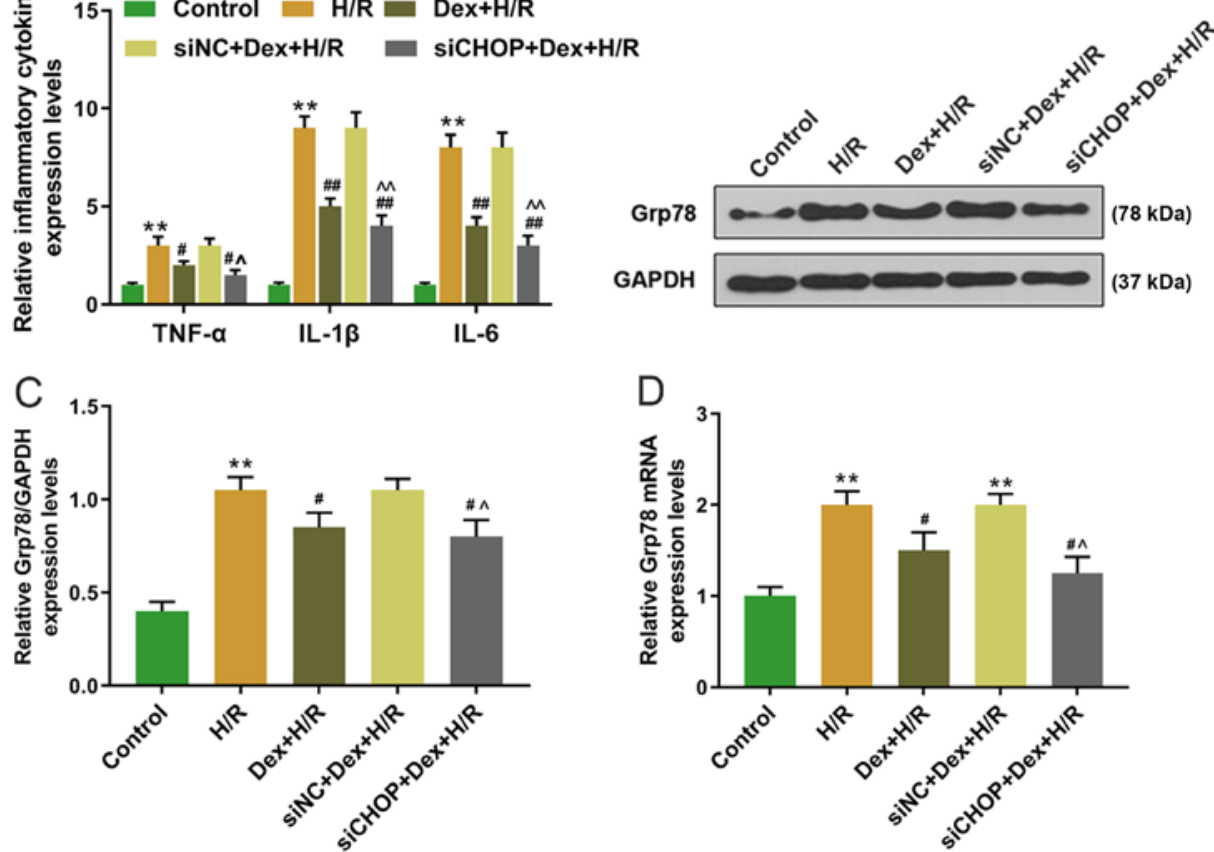

Figure 5. Effects of CHOP silencing on the expression of inflammatory factors and Grp78 in H9C2 cells. (A) Expression levels of TNF- $\alpha$, IL-1 $\beta$ and IL-6 in H9C2 cells were detected by RT-qPCR. (B-D) Expression levels of Grp78 in H9C2 cells were determined by (B and C) western blotting and (D) RT-qPCR. ${ }^{* *} \mathrm{P}<0.001$ vs. control; ${ }^{~} \mathrm{P}<0.05,{ }^{\# \#} \mathrm{P}<0.001$ vs. $\mathrm{H} / \mathrm{R} ;{ }^{\wedge} \mathrm{P}<0.05,{ }^{\wedge} \mathrm{P}<0.001$ vs. siNC+Dex+HR. TNF, tumor necrosis factor; IL, interleukin; RT-qPCR, reverse transcription-quantitative PCR; Dex, dexmedetomidine; H/R, hypoxia/reoxygenation; si, small interfering; NC, negative control; CHOP, C/EBP-homologous protein.

overexpression on cell viability was then measured; compared with the $\mathrm{H} / \mathrm{R}$ and $\mathrm{Dex}+\mathrm{H} / \mathrm{R}$ groups, cell viability was significantly lower in the CHOP+Dex+H/R group (Fig. 6D). The $\mathrm{CHOP}+\mathrm{Dex}+\mathrm{H} / \mathrm{R}$ group exhibited significantly higher LDH levels and apoptotic rates compared with the H/R and
Dex+H/R groups (Fig. 6E-G). Furthermore, the expression levels of TNF- $\alpha$, IL-1 $\beta$ and IL- 6 were significantly lower in the Dex $+\mathrm{H} / \mathrm{R}$ and $\mathrm{NC}+\mathrm{Dex}+\mathrm{H} / \mathrm{R}$ groups, but significantly higher in the CHOP+Dex+H/R group compared with the H/R group (Fig. 7A). The Grp78 protein and mRNA expression 
A
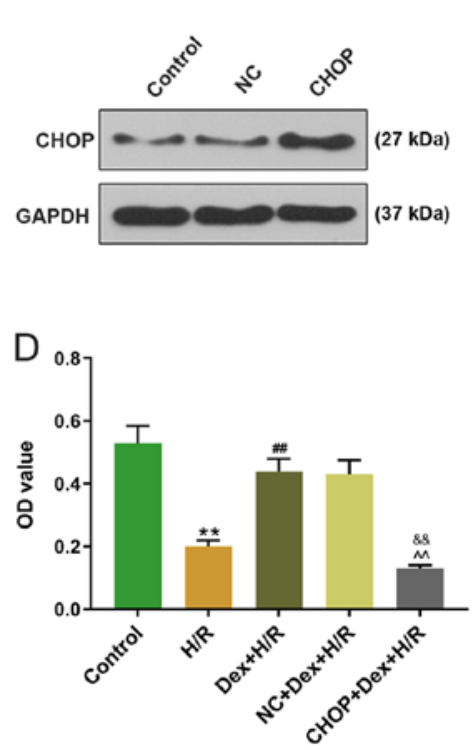
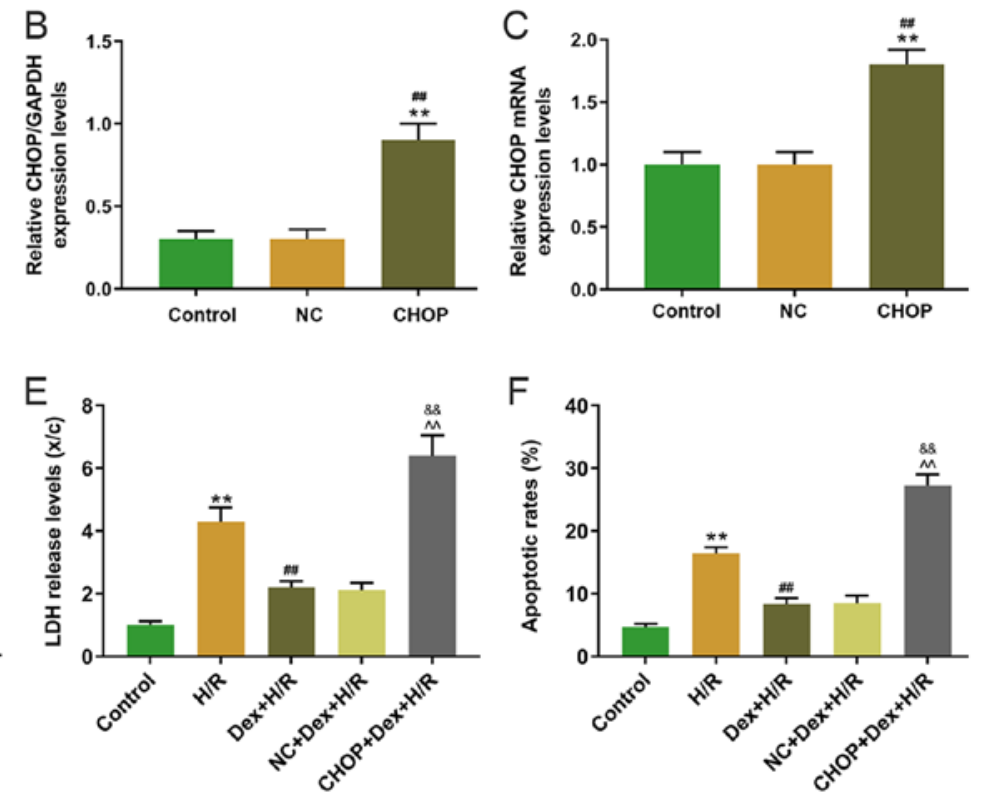

G
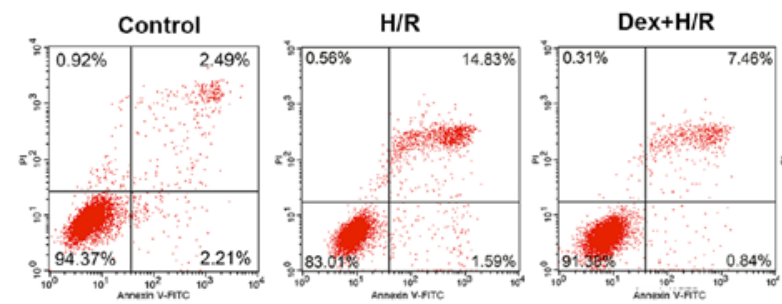

$\mathrm{NC}+$ Dex $+\mathrm{H} / \mathrm{R}$

CHOP+Dex+H/R

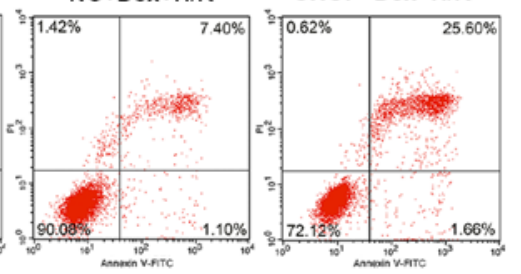

Figure 6. Transfection efficiency of CHOP and effects of CHOP overexpression on cell viability, LDH level and apoptosis in H9C2 cells. (A-C) Expression levels of CHOP were determined by (A and B) western blotting and (C) RT-qPCR. (D) Cell viability of H9C2 cells was determined by MTT assay at $24 \mathrm{~h}$. (E) LDH levels of H9C2 cells determined by 2,4-dinitrophenylhydrazine colorimetric assay. (F and G) Apoptotic rates of $\mathrm{H} 9 \mathrm{C} 2$ cells were determined by flow cytometry. ${ }^{* *} \mathrm{P}<0.001$ vs. Control; ${ }^{\# \#} \mathrm{P}<0.001$ vs. $\mathrm{NC}$ or $\mathrm{H} / \mathrm{R}$; ${ }^{\& \&} \mathrm{P}<0.001$ vs. Dex $+\mathrm{H} / \mathrm{R} ;{ }^{\wedge} \mathrm{P}<0.001$ vs. NC+Dex+HR. CHOP, C/EBP-homologous protein; RT-qPCR, reverse transcription-quantitative PC; LDH, lactate dehydrogenase; H/R, hypoxia/reoxygenation; Dex, dexmedetomidine; NC, negative control; OD, optical density; PI, propidium iodide.
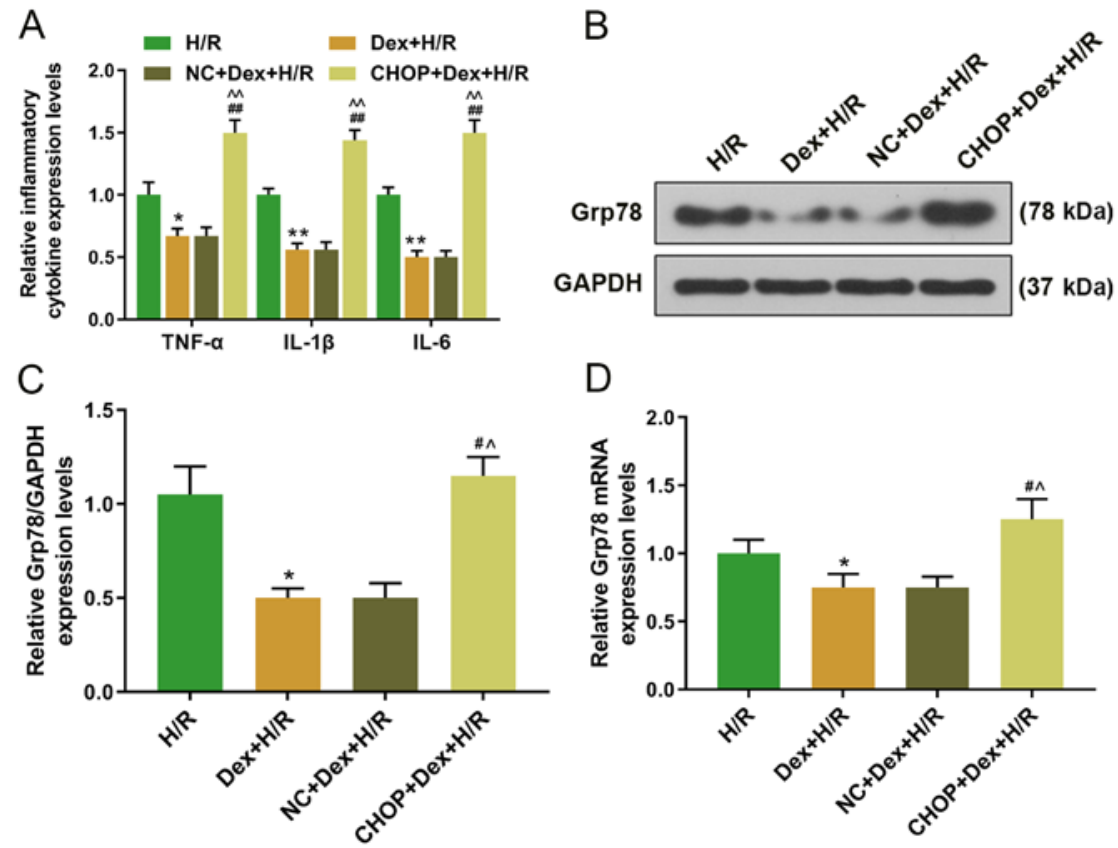

Figure 7. Effects of CHOP overexpression on the expression levels of inflammatory factors and Grp78 in H9C2 cells. (A) Expressions of TNF- $\alpha$, IL-1 $\beta$ and IL-6 in H9C2 were detected by RT-qPCR. (B and C) Protein and (D) mRNA expression levels of Grp78 in H9C2 cells were determined by (B and C) western blotting (D) and RT-qPCR. "P<0.05, ${ }^{* *} \mathrm{P}<0.001$ vs. $\mathrm{H} / \mathrm{R} ;{ }^{*} \mathrm{P}<0.05,{ }^{\# \#} \mathrm{P}<0.001$ vs. Dex $+\mathrm{H} / \mathrm{R} ;{ }^{\wedge} \mathrm{P}<0.05,{ }^{\wedge} \mathrm{P}<0.001$ vs. NC+Dex+H/R. TNF, tumor necrosis factor; IL, interleukin; RT-qPCR, reverse transcription-quantitative PCR; Dex, dexmedetomidine; H/R, hypoxia/reoxygenation; NC, negative control; CHOP, C/EBP-homologous protein. 

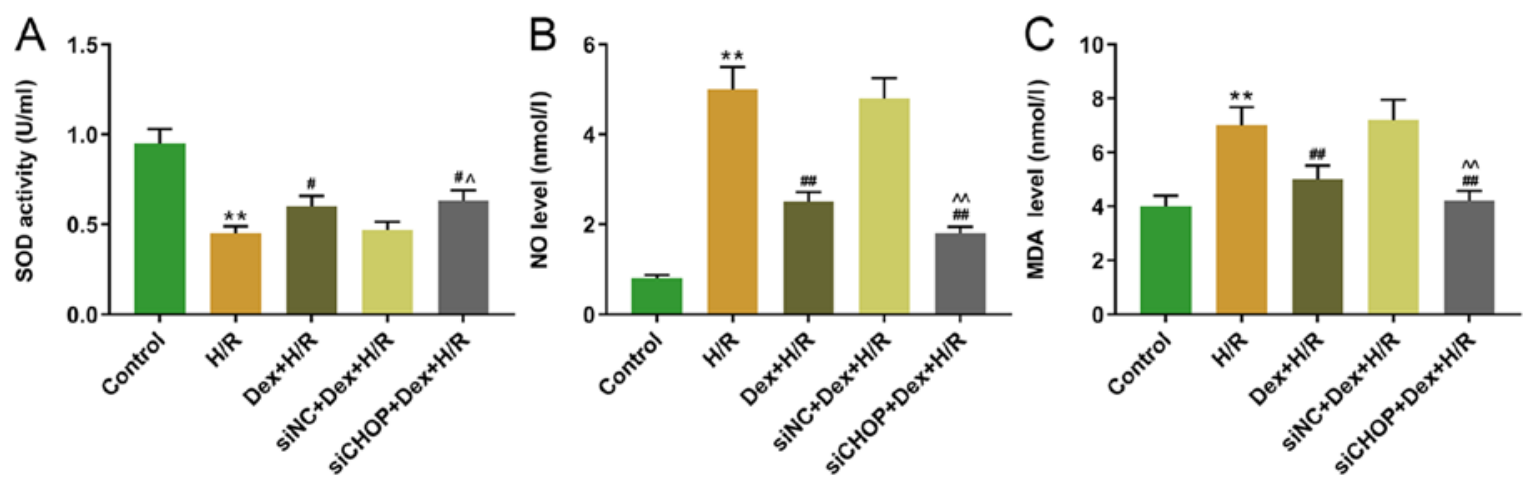

Figure 8. Effects of CHOP knockdown on the SOD activity, and NO and MDA levels in H/R-induced H9C2 cells. The levels of (A) SOD, (B) NO and (C) MDA were measured using ELISA kits. ${ }^{* *} \mathrm{P}<0.001$ vs. H/R; ${ }^{\#} \mathrm{P}<0.05$ and ${ }^{\# \#} \mathrm{P}<0.001$ vs. Dex+H/R; ${ }^{\wedge} \mathrm{P}<0.05$ and ${ }^{\wedge} \mathrm{P}<0.001$ vs. siNC+Dex+H/R. CHOP, C/EBP-homologous protein; SOD, superoxide dismutase; NO, nitric oxide; MDA, malondialdelyde; H/R, hypoxia/reoxygenation; Dex, dexmedetomidine; si, small interfering; NC, negative control.

levels were significantly higher in the $\mathrm{CHOP}+\mathrm{Dex}+\mathrm{H} / \mathrm{R}$ group compared with the Dex+H/R group (Fig. 7B-D).

Effects of silencing CHOP on the SOD activity and NO and MDA levels in $H / R$-induced $H 9 C 2$ cells. The effects of silencing CHOP on H/R-induced H9C2 cells were further observed by measuring SOD activity, as well as MDA and NO levels. The results demonstrated that the SOD activity was significantly decreased in the H/R-group compared with the control group, and that the SOD activity was significantly higher in the Dex $+\mathrm{H} / \mathrm{R}$ and siCHOP+Dex $+\mathrm{H} / \mathrm{R}$ groups compared with that in the $\mathrm{H} / \mathrm{R}$ and siNC+Dex+H/R groups, respectively (Fig. 8A). In addition, the NO and MDA levels were significantly higher in the H/R group compared with the control group, but significantly lower in the Dex $+\mathrm{H} / \mathrm{R}$ and siCHOP+ Dex $+\mathrm{H} / \mathrm{R}$ groups compared with the HR and siNC+ Dex+H/R groups (Fig. 8B and C).

\section{Discussion}

Dex has been demonstrated to reduce H/R-induced damage in primary neonatal rat cardiomyocytes (25). In addition, Dex reduces $\mathrm{H}_{2} \mathrm{O}_{2}$-induced cardiomyocyte apoptosis in neonatal rats through mitochondrial and endoplasmic reticulum-mediated oxidative stress pathways (26). To explore the mechanism of Dex pretreatment in the present study, an H/R model was constructed in $\mathrm{H} 9 \mathrm{C} 2$ cells using sodium dithionite. Sodium dithionite depletes oxygen in the culture medium and simulates an anoxic environment, which causes hypoxic injury in cells without damaging the cell membrane; thus, it is frequently used to induce H/R injury in cells $(27,28)$. In the present study, the H/R model was established with or without the pretreatment of Dex; the results demonstrated that $H / R$ significantly reduced the viability of $\mathrm{H} 9 \mathrm{C} 2$ cells, promoted apoptosis and increased the expression levels of LDH and inflammatory factors, whereas Dex pretreatment prior to $\mathrm{H} / \mathrm{R}$ increased the cell viability and suppressed the release of LDH and inflammatory factors. LDH occurs ubiquitously in cardiomyocytes and is released into the blood upon damage to the cell membrane (29). Accordingly, the level of LDH in the supernatant of the culture medium may reflect the degree of cardiomyocyte injury (30-32). In corroboration with the results of the present study, previous studies have demonstrated that the level of LDH is significantly higher in the H/R-induced I/R injury compared with the control in cardiomyocytes (33-35). The inflammatory factors TNF- $\alpha$, IL-1 $\beta$ and IL- 6 are commonly recognized as inflammatory indicators (36). TNF- $\alpha$ and IL-1 $\beta$ are responsible for the stimulation of chemokines and the secretion of adhesion molecules in ischemic tissues, and IL-6 is responsible for the regulation of inflammation $(37,38)$. Previous studies have reported that Dex induces multiple protective effects on MIRI (39), and such findings were further supported by the present study. Yu et al (40) have reported that microRNA-665 and Dex protect cardiomyocytes against I/R injury caused by oxide stress and suppress apoptosis. Additionally, by inhibiting the expression of inflammatory cytokines, Dex attenuates the I/R injury induced by bilateral renal pedicle clamping (41).

The present study further explored the effects of CHOP on $\mathrm{H} 9 \mathrm{C} 2$ cells induced by H/R. Yang et al (42) have observed that the expression levels of CHOP and Grp78 are significantly upregulated in cardiomyocytes following I/R. During the H/R process, high CHOP and Grp78 expression levels in $\mathrm{H} 9 \mathrm{C} 2$ cells are present (43). CHOP serves a role in the apoptosis signaling pathways $(44,45)$. CHOP and Grp78 are endoplasmic reticulum (ER) stress proteins and are widely recognized as ER stress markers (46). Evidence suggests important roles for ER stress proteins in the cardiomyocyte apoptosis caused by $\mathrm{H} / \mathrm{R}$ process and its regulation on $\mathrm{CHOP}$ in ER stress-induced autophagy $(47,48)$. In H/R-induced H9C2 cell autophagy, the high expression level of CHOP is reduced by the inhibition of ER stress (49). Liu et al (26) have reported that Dex alleviates cardiomyocyte apoptosis induced by $\mathrm{H}_{2} \mathrm{O}_{2}$ via ER stress pathways. Furthermore, Dex treatment has been observed to attenuate cerebral I/R injury by moderating the protein kinase RNA-like endoplasmic reticulum kinase/CHOP/Caspase-11 pathway through inhibition of the expression of ER stress-related apoptotic pathway proteins (50). In human umbilical vein endothelial cells, pretreatment with Dex increases cell the survival rate, decreases expression of $\mathrm{CHOP}$ and caspase- 3 protein, and the apoptotic rate of $\mathrm{H} / \mathrm{R}$-induced cells, suggesting a possible association between Dex and the CHOP signaling pathway in H/R induced apoptosis (51). In the present study, 
western blotting and RT-qPCR demonstrated that pretreatment with Dex significantly suppressed the H/R-induced high expression levels of CHOP and Grp78, suggesting a potential association between Dex and the CHOP signaling pathway. Additionally, in H/R-injured cells, knockdown of CHOP expression promoted cell viability, inhibited apoptosis and suppressed the release of LDH and expression of inflammatory factors and Grp78, whereas the overexpression of CHOP aggravated the cell injury induced by $\mathrm{H} / \mathrm{R}$. These results suggested that the block of CHOP may attenuate the negative effects of $\mathrm{H} / \mathrm{R}$ on cell viability and apoptosis, release of LDH and the expression of inflammatory factors and $\mathrm{Grp} 78$ of $\mathrm{H} 9 \mathrm{C} 2$ cells, and that the overexpression of CHOP inhibited the protective effects of Dex on cardiomyocytes.

However, the present study is still not rigorous enough; the effects of Dex on the cardiomyocytes of H/R-injured neonatal mice need further research. In future studies, an H/R injury mouse model will be established or neonatal mouse cardiomyocytes will be selected for research.

In conclusion, the present study explored the effects of Dex on H/R-induced H9C2 cells and observed that the pretreatment with Dex may alleviate H/R-induced cell injury through regulating the $\mathrm{CHOP}$ pathway.

\section{Acknowledgements}

Not applicable.

\section{Funding}

No funding was received.

\section{Availability of data and materials}

The datasets used and/or analyzed during the present study are available from the corresponding author on reasonable request.

\section{Authors' contributions}

XS, ZL and JL made substantial contributions to the conception and design of the study, data acquisition, analysis and interpretation, drafted the manuscript and critically revised it for important intellectual content. All authors are accountable for all aspects of the work in ensuring that questions related to the accuracy or integrity of the work are appropriately investigated and resolved. All authors read and approved the final manuscript.

\section{Ethics approval and consent to participate}

Not applicable.

\section{Patient consent for publication}

Not applicable.

\section{Competing interests}

The authors declare that they have no competing interests.

\section{References}

1. Kloner RA, Shi J, Dai W, Carreno J and Zhao L: Remote ischemic conditioning in acute myocardial infarction and shock states. J Cardiovasc Pharmacol Ther 25: 103-109, 2020.

2. Cooper WA, Corvera JS, Thourani VH, Puskas JD, Craver JM, Lattouf OM and Guyton RA: Perfusion-assisted direct coronary artery bypass provides early reperfusion of ischemic myocardium and facilitates complete revascularization. Ann Thorac Surg 75: 1132-1139, 2003.

3. Walker AC and Johnson NJ: Critical care of the post-cardiac arrest patient. Cardiol Clin 36: 419-428, 2018.

4. Wu D, Wang J, Li H, Xue M, Ji A and Li Y: Role of hydrogen sulfide in ischemia-reperfusion injury. Oxid Med Cell Longev 2015: 186908, 2015.

5. Faust KB, Chiantella V, Vinten-Johansen J and Meredith JH: Oxygen-derived free radical scavengers and skeletal muscle ischemic/reperfusion injury. Am Surg 54: 709-719, 1988.

6. Dong HJ, Li J, Zhan H, Li Y and Su RB: Tea polyphenols promote cardiac function and energy metabolism in ex vivo rat heart with ischemic/reperfusion injury and inhibit calcium inward current in cultured rat cardiac myocytes. Nan Fang Yi Ke Da Xue Xue Bao 36: 604-608, 2016.

7. Li JP, Guo LL, Chen Z, Wang R and Wang J: Relationship between calcium overload and myocardial ischemia reperfusion injury and intervention strategy of Chinese herbal medicine. Zhongguo Zhong Yao Za Zhi 41: 2168-2173, 2016 (In Chinese).

8. Francis A and Baynosa R: Ischaemia-reperfusion injury and hyperbaric oxygen pathways: A review of cellular mechanisms. Diving Hyperb Med 47: 110-117, 2017.

9. Zendedel A, Gharibi Z, Anbari K, Abbaszadeh A, Khayat ZK, Khorramabadi RM, Soleymaninejad M and Gholami M: Selenium ameliorate peripheral nerve ischemic-reperfusion injury via decreased TNF- $\alpha$. Biol Trace Elem Res 176: 328-337, 2017.

10. Halladin NL: Oxidative and inflammatory biomarkers of ischemia and reperfusion injuries. Dan Med J 62: B5054, 2015.

11. Laubach VE and Sharma AK: Mechanisms of lung ischemia-reperfusion injury. Curr Opin Organ Transplant 21: 246-252, 2016.

12. Li Y, Zhu X, Liu X, Du A and Yu B: miR-200a mediates protection of thymosin $\beta-4$ in cardiac microvascular endothelial cells as a novel mechanism under hypoxia-reoxygenation injury. J Cell Biochem 120: 19098-19106, 2019.

13. Gao C, Wang R, Li B, Guo Y, Yin T, Xia Y, Zhang F, Lian K, Liu Y, Wang H, et al: TXNIP/Reddl signalling and excessive autophagy: A novel mechanism of myocardial ischaemia/reperfusion injury in mice. Cardiovasc Res 116: 645-657, 2020.

14. Manning JR, Thapa D, Zhang M, Stoner MW, Traba J, Corey C, Shiva S, Sack MN and Scott I: Loss of GCN5L1 in cardiac cells disrupts glucose metabolism and promotes cell death via reduced Akt/mTORC2 signaling. Biochem J 476: 1713-1724, 2019.

15. El Baz MM and Farahat TEM: Efficacy of adding dexmedetomidine to intra-articular levobupivacaine on postoperative pain after knee arthroscopy. Anesth Essays Res 13: 254-258, 2019.

16. Sha J, Zhang H, Zhao Y, Feng X, Hu X, Wang C, Song M and Fan H: Dexmedetomidine attenuates lipopolysaccharide-induced liver oxidative stress and cell apoptosis in rats by increasing GSK-3 $3 /$ MKP-1/Nrf2 pathway activity via the $\alpha 2$ adrenergic receptor. Toxicol Appl Pharmacol 364: 144-152, 2019.

17. Chen L, Cao J, Cao D, Wang M, Xiang H, Yang Y, Ying T and Cong $\mathrm{H}$ : Protective effect of dexmedetomidine against diabetic hyperglycemia-exacerbated cerebral ischemia/reperfusion injury: An in vivo and in vitro study. Life Sci 235: 116553, 2019.

18. Chen N, Chen X, Xie J, Wu C and Qian J: Dexmedetomidine protects aged rats from postoperative cognitive dysfunction by alleviating hippocampal inflammation. Mol Med Rep 20: 2119-2126, 2019.

19. Wang Q, Tan Y, Zhang N, Xu Y, Wei W, She Y, Bi X, Zhao B and Ruan X: Dexmedetomidine inhibits activation of the MAPK pathway and protects PC12 and NG108-15 cells from lidocaine-induced cytotoxicity at its maximum safe dose. Biomed Pharmacother 91: 162-166, 2017.

20. Yang CL, Tsai PS and Huang CJ: Effects of dexmedetomidine on regulating pulmonary inflammation in a rat model of ventilator-induced lung injury. Acta Anaesthesiol Taiwan 46: 151-159, 2008.

21. Jacob H, Stanisavljevic L, Storli KE, Hestetun KE, Dahl O and Myklebust MP: A four-microRNA classifier as a novel prognostic marker for tumor recurrence in stage II colon cancer. Sci Rep 8: $6157,2018$. 
22. Liu YJ, Wang DY, Yang YJ and Lei WF: Effects and mechanism of dexmedetomidine on neuronal cell injury induced by hypoxia-ischemia. BMC Anesthesiol 17: 117, 2017.

23. Gonzalez Villarreal C, Said Fernandez S, Soto Dominguez A Padilla Rivas G, Garza Treviño E, Rodriguez Rocha H and Martinez Rodriguez H: Bone marrow mesenchymal stem cells: Improving transgene expression level, transfection efficiency and cell viability. J BUON 23: 1893-1903, 2018.

24. Livak KJ and Schmittgen TD: Analysis of relative gene expression data using real-time quantitative PCR and the 2(-Delta Delta C(T)) method. Methods 25: 402-408, 2001.

25. Peng K, Qiu Y, Li J, Zhang ZC and Ji FH: Dexmedetomidine attenuates hypoxia/reoxygenation injury in primary neonatal rat cardiomyocytes. Exp Ther Med 14: 689-695, 2017.

26. Liu XR, Li T, Cao L, Yu YY, Chen LL, Fan XH, Yang BB and Tan XQ: Dexmedetomidine attenuates H2O2-induced neonatal rat cardiomyocytes apoptosis through mitochondria- and ER-medicated oxidative stress pathways. Mol Med Rep 17: 7258-7264, 2018

27. Jiang J, Chen DY, Liu ZT, Chen F, Zhang JJ, Cui J and Pang J: Effect of N-perfluorooctane on hypoxia/reoxygenation injury in human umbilical vein endothelial cells. Acta Cardiol Sin 32 716-722, 2016

28. Chai YL, Xu JZ, Zhang YL and Sheng GT: Effects of probucol on cultured human umbilical vein endothelial cells injured by hypoxia/reoxygenation. Genet Mol Res 15: 15016752, 2016.

29. Lin CX, Gu JL and Cao JM: The acute toxic effects of platinum nanoparticles on ion channels, transmembrane potentials of cardiomyocytes in vitro and heart rhythm in vivo in mice. Int J Nanomedicine 14: 5595-5609, 2019.

30. Fan L, Zhou W, Zhang L, Jiang D, Zhao Q and Liu L: Sitagliptin protects against hypoxia/reoxygenation $(\mathrm{H} / \mathrm{R})$-induced cardiac microvascular endothelial cell injury. Am J Transl Res 11: 2099-2107, 2019

31. Kong QR, Ji DM, Li FR, Sun HY and Wang QX: MicroRNA-221 promotes myocardial apoptosis caused by myocardial ischemia-reperfusion by down-regulating PTEN. Eur Rev Med Pharmacol Sci 23: 3967-3975, 2019.

32. Zhang Y, Zhang H, Zhang Z, Li S, Jiang W, Li X and Lv J: IncRNA MALAT1 cessation antagonizes hypoxia/reoxygenation injury in hepatocytes by inhibiting apoptosis and inflammation via the HMGB1-TLR4 axis. Mol Immunol 112: 22-29, 2019.

33. Ge L, Cai Y, Ying F, Liu H, Zhang D, He Y, Pang L, Yan D, $\mathrm{Xu} \mathrm{A}, \mathrm{Ma} \mathrm{H}$ and Xia Z: miR-181c-5p exacerbates hypoxia/reoxygenation-induced cardiomyocyte apoptosis via targeting PTPN4 Oxid Med Cell Longev 2019: 1957920, 2019.

34. Chen Y, Wang H, Zhang Y, Wang Z, Liu S and Cui L: Pretreatment of ghrelin protects $\mathrm{H} 9 \mathrm{c} 2$ cells against hypoxia/reoxygenation-induced cell death via PI3K/AKT and AMPK pathways. Artif Cells Nanomed Biotechnol 47: 2179-2187, 2019.

35. Yang $\mathrm{H}$, Wang $\mathrm{C}$, Zhang $\mathrm{L}, \mathrm{Lv} \mathrm{J}$ and $\mathrm{Ni} \mathrm{H}$ : Rutin alleviates hypoxia/reoxygenation-induced injury in myocardial cells by up-regulating SIRT1 expression. Chem Biol Interact 297: 44-49, 2019.

36. Soomro AH, Khan E, Noori S, Lone MA, Syal Z and Sheikh S: Assessment of cytokine release against oral mucosal cell line culture (TR146) stimulated by neutrophil elastase associated with Behcet's disease. Int J Dent 2019: 6095628, 2019.

37. Zhang Q, Weng Y, Jiang Y, Zhao S, Zhou D and Xu N Overexpression of miR-140-5p inhibits lipopolysaccharide-induced human intervertebral disc inflammation and degeneration by downregulating toll-like receptor 4 . Oncol Rep 40: 793-802, 2018

38. Peters MC, McGrath KW, Hawkins GA, Hastie AT, Levy BD, Israel E, Phillips BR, Mauger DT, Comhair SA, Erzurum SC, et al: Plasma interleukin-6 concentrations, metabolic dysfunction, and asthma severity: A cross-sectional analysis of two cohorts. Lancet Respir Med 4: 574-584, 2016.
39. Ren J, Li C, Liu Y, Liu H and Dong Z: Protective effect of dexmedetomidine against myocardial ischemia-reperfusion injury in rabbits. Acta Cir Bras 33: 22-30, 2018

40. Yu J, Yang W, Wang W, Wang Z, Pu Y, Chen H, Wang F and Qian J: Involvement of miR-665 in protection effect of dexmedetomidine against oxidative stress injury in myocardial cells via CB2 and CK1. Biomed Pharmacother 115: 108894, 2019.

41. Xu Z, Wang D, Zhou Z, Chen Q, Zhang D, Chen S, Jiang H, Jia C and Liu X: Dexmedetomidine attenuates renal and myocardial ischemia/reperfusion injury in a dose-dependent manner by inhibiting inflammatory response. Ann Clin Lab Sci 49: 31-35, 2019.

42. Yang TR, Zhang T, Mu NH, Ruan LB, Duan JL, Zhang RP and Miao YB: Resina draconis inhibits the endoplasmic-reticulum-induced apoptosis of myocardial cells via regulating miR-423-3p/ERK signaling pathway in a tree shrew myocardial ischemia-reperfusion model. J Biosci 44: 53, 2019.

43. Guan G, Zhang J, Liu S, Huang W, Gong Y and Gu X Glucagon-like peptide-1 attenuates endoplasmic reticulum stress-induced apoptosis in $\mathrm{H} 9 \mathrm{c} 2$ cardiomyocytes during hypoxia/reoxygenation through the GLP-1R/PI3K/Akt pathways. Naunyn Schmiedebergs Arch Pharmacol 392: 715-722, 2019.

44. Hu H, Tian M, Ding C and Yu S: The C/EBP homologous protein (CHOP) transcription factor functions in endoplasmic reticulum stress-induced apoptosis and microbial infection. Front Immunol 9: 3083, 2019.

45. Zhao J, Xiang X, Zhang H, Jiang D, Liang Y, Qing W, Liu L, Zhao Q and He Z: CHOP induces apoptosis by affecting brain iron metabolism in rats with subarachnoid hemorrhage. Exp Neurol 302: 22-33, 2018.

46. Lei Y, Wang S, Ren B, Wang J, Chen J, Lu J, Zhan S, Fu Y, Huang $\mathrm{L}$ and Tan J: CHOP favors endoplasmic reticulum stress-induced apoptosis in hepatocellular carcinoma cells via inhibition of autophagy. PLoS One 12: e0183680, 2017.

47. Xu JQ, Chen B, Hu HX, Yue RC, Zhang S, Xu L, Wang H, Li Q, Tan CY, Chen HY and Zhang RY: Lycopene protects against hypoxia/reoxygenation injury in mouse cardiomyocytes by inhibiting endoplasmic reticulum stress induced apoptosis. Zhonghua Xin Xue Guan Bing Za Zhi 44: 518-523, 2016 (In Chinese).

48. Cao L, Chen Y, Zhang Z, Li Y and Zhao P: Endoplasmic reticulum stress-induced NLRP1 inflammasome activation contributes to myocardial ischemia/reperfusion injury. Shock 51: 511-518, 2019.

49. Guan G, Yang L, Huang W, Zhang J, Zhang P, Yu H, Liu S and $\mathrm{Gu} X$ : Mechanism of interactions between endoplasmic reticulum stress and autophagy in hypoxia/reoxygenation-nduced injury of H9c2 cardiomyocytes. Mol Med Rep 20: 350-358, 2019.

50. Liu C, Fu Q, Mu R, Wang F, Zhou C, Zhang L, Yu B, Zhang Y, Fang $\mathrm{T}$ and Tian F: Dexmedetomidine alleviates cerebral ischemia-reperfusion injury by inhibiting endoplasmic reticulum stress dependent apoptosis through the PERK-CHOP-Caspase-11 pathway. Brain Res 1701: 246-254, 2018.

51. Yang C, Gao C, Yu M, Li B, Lu Y and Lü G: Effect of dexmedetomidine pretreatment on hypoxia/reoxygenation-induced injury in human umbilical vein endothelial cells and the possible mechanism. Zhonghua Yi Xue Za Zhi 94: 3527-3530, 2014 (In Chinese).

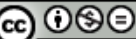

This work is licensed under a Creative Commons Attribution-NonCommercial-NoDerivatives 4.0 International (CC BY-NC-ND 4.0) License. 